\title{
Antibiofilm Activity of Nystatin, Aspirin and EDTA Against Candida albicans Isolated from Iraqi Women with Vulvovaginitis
}

\author{
Noor Naser Raheem ${ }^{1}$, Kais Kassim Ghaima ${ }^{2 *}$ \\ ${ }^{1}$ Research Scholar, M Sc Student, Kamal Al-Samarrai Hospital, Ministry of Health, Baghdad, Iraq, \\ ${ }^{2}$ Assistant Professor, Institute of Genetic Engineering and Biotechnology for Postgraduate Studies, \\ University of Baghdad, Baghdad, Iraq
}

\begin{abstract}
The vulvovaginitis candidiasis is often associated with biofilm formation by Candida albicans and using of antifungal agents against $C$. albicans biofilms is urgently needed. Microtiter plate assay using crystal violet was used for detection the ability of Candida albicans to form biofilm and the microtiter broth dilution method was used for determination the minimum inhibitory concentrations (MICs). Out of 42 Candida albicans isolated from vulvovaginitis, $37(88 \%)$ can produce biofilm at the varying degrees. Twenty-eight (75.7\%) isolates could form a strong biofilm. The results of minimum inhibitory concentrations (MICs) of Nystatin, Aspirin and EDTA (Ethylenediaminetetraacetic acid) against 28 C. albicans isolates which formed the strong biofilm, revealed that range of concentrations of Nystatin were $(6.25-100 \mu \mathrm{g} / \mathrm{ml})$, while the MICs of aspirin and EDTA were more than $1000 \mu \mathrm{g} / \mathrm{ml}$. It was obvious that the Nystatin had the inhibitory activity at the concentrations 6.25 and $12.5 \mu \mathrm{g} / \mathrm{ml}$. The highest antibiofilm activity by Nystatin were demonstrated at the subinhibitory concentration $50 \mu \mathrm{g} / \mathrm{ml}$ with biofilm eradication percent $(75.80 \%)$, while the lowest antifungal effect (2.86-10.70\%) was at very low concentrations $(3.125-6.25 \mu \mathrm{g} / \mathrm{ml})$. Also, there was an obvious biofilm eradication of Aspirin and EDTA at the concentrations 500 and $1000 \mu \mathrm{g} / \mathrm{ml}$ but the effect of aspirin at the concentration $1000 \mu \mathrm{g} / \mathrm{ml}(70.51 \%)$ is more than EDTA $(60.12 \%)$ in contrast with the concentration $500 \mu \mathrm{g} / \mathrm{ml}$, it was found that the effect of EDTA $(51.29 \%)$ is more than aspirin $(34.25 \%)$. In conclusion, the present study highlights the role of Aspirin and EDTA as antibiofilm agents when used with Nystatin which have the ability to inhibit the growth of $C$. albicans in patients with vulvovaginitis.
\end{abstract}

Keywords: Nystatin, Aspirin, EDTA, C. albicans, Biofilm, Vulvovaginitis.

\section{Introduction}

Vulvovaginal candidiasis (VVC) is considered as the main infection caused by Candida albicans. Numerous virulence determinants and escalating resistance to antifungal therapy have contributed to its pathogenicity ${ }^{(1)}$. Some virulence factors such as

\footnotetext{
Corresponding Author:

Kais Kassim Ghaima

Assistant Professor, Institute of Genetic Engineering and Biotechnology for Postgraduate Studies, University of Baghdad, Baghdad, Iraq e-mail: kaiskassim@gmail.com
}

dimorphism and the ability to adhere and form biofilm on medical device and/or the host mucosal epithelium, enhance the pathogenicity of C. albicans $^{(2)}$. Vulvovaginal candidiasis defined as a disorder characterized by signs and symptoms of vaginal inflammation when the Candida species are found and is an ever living problem affecting $70-75 \%$ of women of reproductive age at least once during their life ${ }^{(3)}$. The evolution of drug resistance of Candida species to conventional antifungal agents has been a major medical challenge worldwide; attempt to use the potential antifungal agents with appropriate therapy efficacy and minimum effects is considerably growing ${ }^{(4)}$. The mechanism underlying development of antifungal resistance of $C$. albicans are complex and involve multiple pathways and genes. Further, 
these mechanisms continue to change and evolve and challenging the medical clinic ${ }^{(5)}$. The widespread use of antibiotics, frequent use of indwelling medical devices, and a trend towards increased patient immunosuppression has resulted in a creation of opportunity for clinically important Candida to form biofilms and there is growing evidence of the importance of Candida biofilms in clinical problems ${ }^{(6)}$. Therefore the aim of this study is investigate the biofilm formation of $C$. albicans isolates as the causative agent of vulvovaginitis in Iraqi women, also using of some compounds such as Aspirin and EDTA as antifungal agents against the high antifungal resistant isolates.

\section{Materials and Method}

Candida albicans isolates: In this study, a total of 42 C. albicans clinical strains were collected from women patients with vulvovaginitis from three hospitals in Baghdad, Iraq, during the period from September to December 2019. All strains were previously identified by API Candida system (bioMérieux, France) and confirmed using VITEK 2 compact system (bioMérieux, France).

Quantitative biofilm production assay: The Colonies from all isolates of fresh C. albicans cultures (48 hours) were grown at $37^{\circ} \mathrm{C}$ in Sabouraud dextrose broth medium for 24 hours. Biofilm formation was tested by adding $100 \mu \mathrm{l}$ of this standardized cell suspension to wells of microtiter plates that contained $100 \mu \mathrm{l}$ of fresh Sabouraud dextrose broth media and incubating them at $37^{\circ} \mathrm{C}$ for 48 hours. Thereafter, the medium was removed and planktonic cells were removed by washing the biofilms in phosphate buffered saline. After staining plates with $2 \%$ crystal violet for $20 \mathrm{~m}$, excess stain was removed using water. The plates were air dried and then the dye was resolubilized with absolute ethanol. The optical density (OD) of each well was measured at $570 \mathrm{~nm}$ using Enzyme-Linked Immunosorbent Assay (ELISA) reader (BioTek, Korea). Optical density cut-off value (ODc) was calculated using the equation: average OD of negative control $+(3 * \mathrm{SD}$ of negative control $){ }^{(7)}$.

Minimum inhibitory concentration of Nystatin, Aspirin and EDTA: Nearly, $100 \mu \mathrm{l}(0.5 \mathrm{McF}$ arland $)$ of the $C$. albicans culture was inoculated into each well of a 96-well microtiter plate containing $100 \mu$ l Nystatin, Aspirin and EDTA at different concentrations (0.39-200 $\mu \mathrm{g} / \mathrm{ml})$. Wells without Nystatin, Aspirin and EDTA were used as a positive control while those without Candida were considered as negative controls. After 24 hours incubation at $37^{\circ} \mathrm{C}$, the wells were visually inspected for the growth. The MIC was considered as the lowest concentration of Nystatin, Aspirin and EDTA that inhibits the Yeast growth ${ }^{(8)}$.

Antibiofilm activity of Nystatin, Aspirin and EDTA: This test was performed on four strains that showed strong biofilm formation ability in the biofilm production assay. The effect of different concentrations of Nystatin $(3.125-100 \mu \mathrm{g} / \mathrm{ml})$, while Aspirin and EDTA $(31.25-1000 \mu \mathrm{g} / \mathrm{ml})$ to inhibit the ability of $C$. albicans cells to form a biofilm was assessed using the TCP method adopted by Khodavandi et al. (2011) ${ }^{(9)}$. Nearly, $100 \mu \mathrm{l}$ of $0.5 \mathrm{McF}$ arland yeast cultures was dispensed into each well of 96-well polystyrene microtiter plates in the presence of $100 \mu \mathrm{l}$ of the antibiofilm agent at different concentrations, and plates were incubated at $37^{\circ} \mathrm{C}$ for 48 hours. Antimicrobial agent free wells served as positive controls for the biofilm growth. After incubation, the medium and non-adherent cells were removed and wells were washed three times with sterile PBS. The plates were air dried and then the dye was resolubilized with absolute ethanol. The OD of each well was measured at $570 \mathrm{~nm}$ using ELISA reader (BioTek, Korea). Each assay was performed in triplicates.

Statistical Analysis: The Statistical Analysis System- SAS (2012) ${ }^{(10)}$ program was used to detect the effect of difference factors in study percentage. Chisquare test was used to significant compare between percentage ( 0.05 and 0.01 probability). Least significant difference LSD test (Analysis of Variation-ANOVA) was used to significant compare between means in this study.

\section{Results and Discussion}

Biofilm formation: Out of 42 Candida albicans isolates, $37(88 \%)$ can produce biofilm at the varying degrees. Twenty-eight $(75.7 \%)$ isolates could form a strong biofilm, while 6 isolates were the moderate producer, and only 3 isolates were weak biofilm formers. Also it was found that five isolates don't have the ability to formation the biofilm (table 1). Microtiter plate assay using crystal violet was used for detection the ability of Candida albicans to form biofilm (figure 1). 
Table 1. Distribution of biofilm formation ability among Candida albicans isolates.

\begin{tabular}{|l|c|c|c|c|}
\hline \multirow{2}{*}{ Candida albicans } & \multicolumn{4}{|c|}{ Biofilm formation } \\
\cline { 2 - 5 } & Weak & Moderate & Strong & Negative \\
\hline Total no of Isolate $=42$ & 3 & 6 & 28 & 5 \\
\hline$\%$ & $7.14 \%$ & $14.29 \%$ & $66.67 \%$ & $11.90 \%$ \\
\hline Chi-Square $\left(\chi^{2}\right)$ & \multicolumn{4}{|c|}{$12.073^{* *}$} \\
\hline
\end{tabular}

$* *(\mathrm{P} \leq 0.01)$.

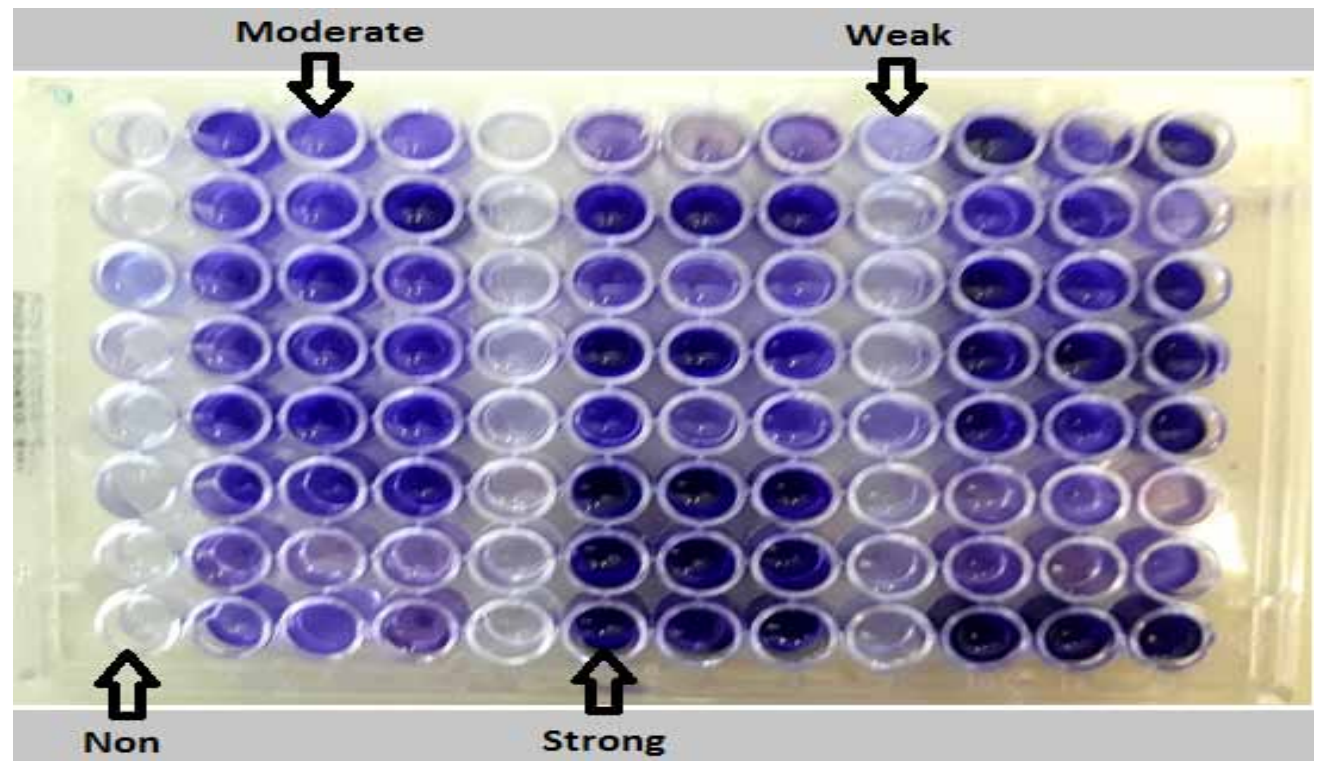

Figure 1. Biofilm formation detection of Candida albicans isolates by microtiter plate assay.

This study revealed that the most of Candida albicans isolated from Iraqi women patients with vulvovaginitis formed a strong biofilm. Many studies demonstrated the ability of Candida albicans clinical isolates to form heterogeneous biofilms. The presence of these communities in vulvovaginitis may explain why $C$. albicans infections remain unresponsive to therapy, and there was a relationship between biofilm formation and antifungal resistance among Candida isolates $(11,12)$. The study of Shreif et al. (2019) ${ }^{(13)}$ in Egypt which included one hundred Candida albicans isolates from patients with nosocomial infections revealed that the biofilm capacity was identified by the microplate method in $58 \%$ of $C$. albicans and the optical density was intense in 20 isolates, moderate in 21 isolates and mild in 17 isolates. The local study of Mohammed et al. (2017) ${ }^{(14)}$ demonstrated that $C$. albicans was the most predominant species among vaginal specimens in percentage (45\%) and all C. albicans isolates were biofilm producers with variable strength, Among vaginal isolates; 10/22 (45.5\%) were weak biofilm formers whereas moderate or strong biofilm formers were $12 / 22(54.5 \%)$. In a previous study, it was found the Candida biofilms have important clinical implications since the biofilm associated with Candida or Gardnerella genital infections may act as a chlamydial reservoir contributing to the transmission of Chlamydia trachomatis in the population, alongside its dissemination in the female upper genital tract ${ }^{(15)}$. The biofilm formation is very important virulence factor in C. albicans, where this species expresses hyphal-specific adhesins and regulators required for adhesion. Also, the morphological dimorphism in Candida albicans supports noticeable phagocyte escape mechanism ${ }^{(16)}$.

The present study investigated the role of some compounds as antibiofilm agents against the biofilm formation in C. albicans isolates, these compounds are Nystatin, Aspirin and EDTA. At first, the minimum inhibitory concentrations (MICs) of these compounds were measured by microdilution method in 96 well microtiter plates with resazurin dye and then detection the antibiofilm concentration by exposing the yeast 
to subinhibitory concentration in the same plate with crystal violet staining.

The results of minimum inhibitory concentrations (MICs) of Nystatin, Aspirin and EDTA against $28 C$. albicans isolates which formed the strong biofilm, revealed that range of concentrations of Nystatin were $(6.25-100 \mu \mathrm{g} / \mathrm{ml})$, while the MICs of aspirin and EDTA were more than $1000 \mu \mathrm{g} / \mathrm{ml}$. The table 2 and figure 2 demonstrated the MICs of 2 isolates by using the double concentrations (from 0.39 to $200 \mu \mathrm{g} / \mathrm{ml}$ ) and it was obvious that there is no effect of Aspirin and EDTA on the growth of $C$. albicans at the used range while the Nystatin had the inhibitory activity at the concentrations 6.25 and $12.5 \mu \mathrm{g} / \mathrm{ml}$ against the isolates 1 and 2 respectively.

Table 2. The minimum Inhibitory Concentrations (MICs) of antibiofilm agents against Candida albicans isolates.

\begin{tabular}{|c|c|c|c|c|c|c|c|c|c|c|c|}
\hline \multirow{2}{*}{ Antibiofilm agent } & \multirow{2}{*}{$\begin{array}{l}\text { Candida } \\
\text { albicans }\end{array}$} & \multicolumn{10}{|c|}{ Minimum Inhibitory Concentration (MIC) $(\mu \mathrm{g} / \mathrm{ml})$} \\
\hline & & 0.39 & 0.78 & 1.56 & 3.12 & 6.25 & 12.5 & 25 & 50 & 100 & 200 \\
\hline \multirow{2}{*}{ Nystatin } & Isolate 1 & & & & & & + & & & & \\
\hline & Isolate 2 & & & & & + & & & & & \\
\hline \multirow{2}{*}{ Asprin } & Isolate 1 & - & - & - & - & - & - & - & - & - & - \\
\hline & Isolate 2 & - & - & - & - & - & - & - & - & - & - \\
\hline \multirow{2}{*}{ EDTA } & Isolate 1 & - & - & - & - & - & - & - & - & - & - \\
\hline & Isolate 2 & - & - & - & - & - & - & - & - & - & - \\
\hline
\end{tabular}

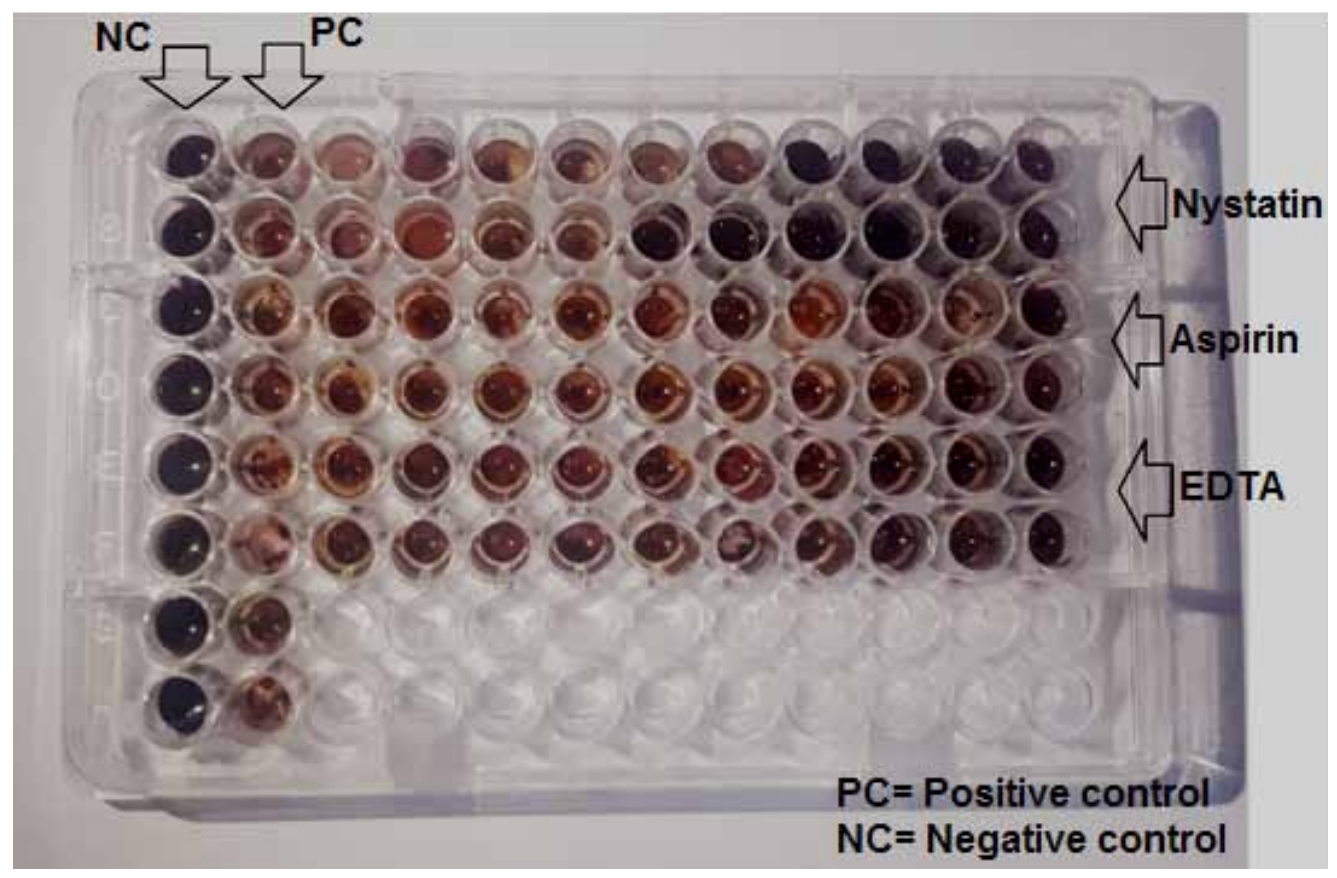

Figure 2. The minimum Inhibitory Concentrations (MICs) of antibiofilm agents against Candida albicans isolates by microtiter plate assay with resazurin dye.

The previous study included 14 yeast strains 7 control strains were investigated regarding their in vitro susceptibility to the polyene antifungal agent nystatin, the Minimum inhibitory concentrations (MICs) for nystatin were measured by both visual examination, and spectrophotometric measuring after 24 and 48 hours incubation time at $36^{\circ} \mathrm{C}$. The visual read-out of growth inhibition revealed MICs for nystatin in a range from 0.625 to $1.25 \mu \mathrm{g} / \mathrm{ml}$ for all Candida species tested, where the Candida albicans strains, and both 
strains of $C$. glabrata and $C$. tropicalis, showed low MIC values $0.625 \mu \mathrm{g} / \mathrm{ml}{ }^{(17)}$. Many previous studies found that nystatin MICs for $C$. albicans isolated from vulvovaginitis ranged from 1 to $16 \mu \mathrm{g} / \mathrm{ml}$, with a MIC inhibiting $90 \%$ of isolates $\left(\mathrm{MIC}_{90}\right)$ of 4 to $16 \mu \mathrm{g} / \mathrm{ml}^{(18,19)}$.

The current study consistent with Al-Bakri et al. (2009) (20) study which indicated to need of high concentrations of Aspirin and EDTA to achieve MIC against $C$. albicans, where Aspirin MIC values (mg/ $\mathrm{ml})$ of 2.03, 1.2 and 2.65 were achieved against $P$. aeruginosa, E. coli and C. albicans, respectively. An EDTA concentration as high as $60 \mathrm{mg} / \mathrm{ml}$ failed to attain the $\mathrm{MBC}$ value, while aspirin $\mathrm{MBC}$ values $(\mathrm{mg} / \mathrm{ml})$ of 4.8, 4.9 and 5.28 were reported against $P$. aeruginosa, E. coli and $C$. albicans, respectively. Also, the results of Cederlund and Mardh (1993) (21) demonstrated that Aspirin possesses a relatively weak broadspectrum antimicrobial activity where relatively high concentrations of aspirin are needed to effect biostatic activities and even higher concentrations are needed for biocidal activities. Antipyretics such as Aspirin primarily act by inhibiting prostaglandin synthesis. Fungi produce prostaglandins, and although their exact function is uncertain, it is thought that they influence virulence, in particular controlling the yeast-to-hypha transition and biofilm production. Also, changing the surface hydrophobicity of microbes and modifying the susceptibility of microbes to antimicrobial therapy ${ }^{(22 ; 23)}$.

It is also known that anticoagulant and calcium and magnesium chelator EDTA (Ethylenediaminetetraacetic Acid) may have antimicrobial activity against several Gram-positive bacteria and Candida spp. EDTA forms chelation with divalent metals such as $\operatorname{Mg}(2+)$ and $\mathrm{Ca}(2+)$, which are required by various essential enzymes $^{(24,25)}$. EDTA demonstrated the highest antifungal activity in comparison with routine antifungal drugs by prevent the binding of $C$ albicans to the proteins in a dose-dependent manner and reduces the growth of $C$ albicans by removing calcium from the cell walls and causing collapses in the cell wall, and by inhibiting enzyme reaction ${ }^{(26)}$. EDTA acts on the cell surface, resulting in the rapid release of approximately half of the lipopolysaccharide with a negligible loss of other cell components. The disruption of the lipopolysaccharide structure in the outer membrane of Gram-negative bacteria occurs because EDTA chelates divalent cations. The release of lipopolysaccharides increases the membrane permeability to other agents, hence the

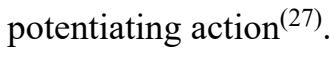

The effect of some antifungal and antibiofilm agents (Nystatin, Aspirin and EDTA) on the biofilm formation of $C$. albicans isolates were achieved using microtiter plate assay with crystal violet staining (figure 3 ).

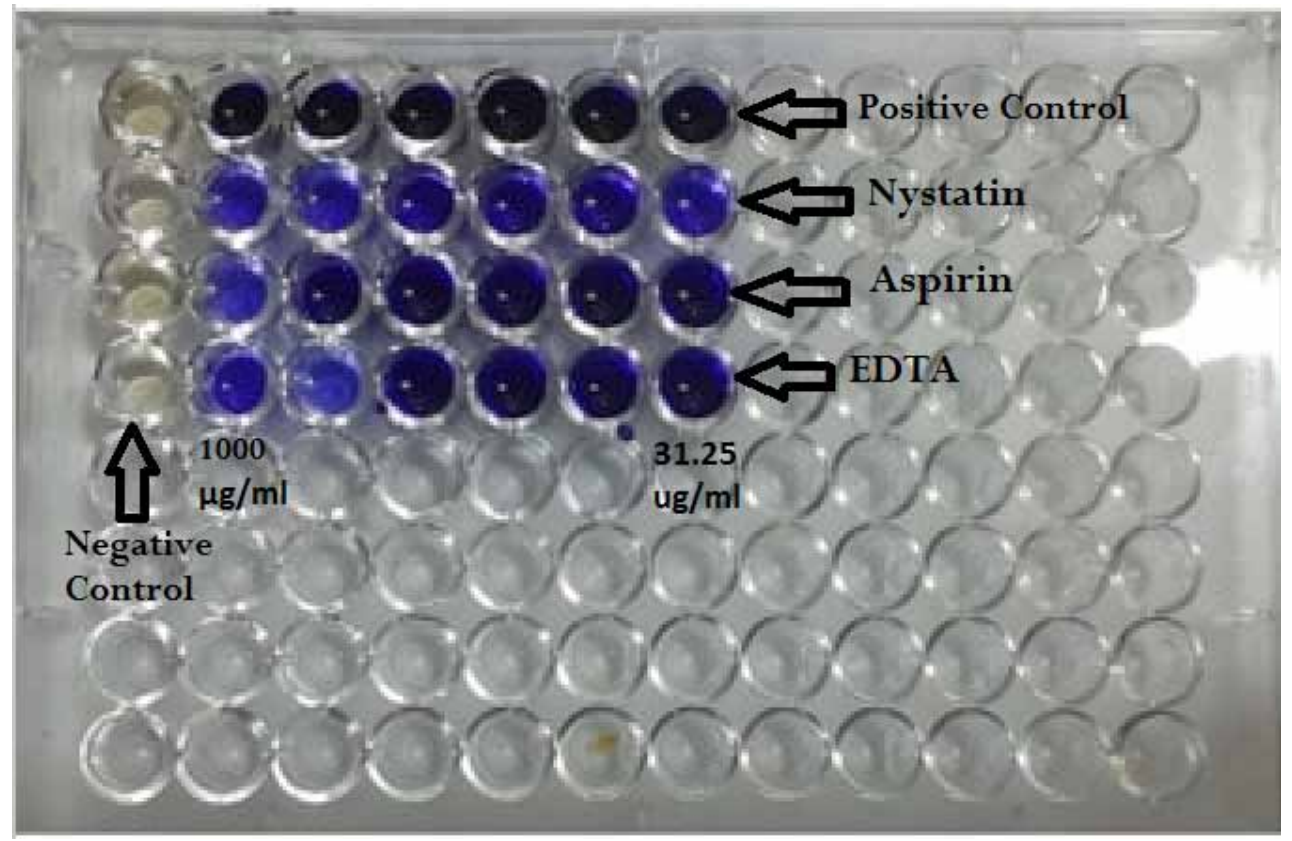

Figure 3. Biofilm quantification by microtiter plate assay of Candida albicans (isolate 5) at different subinhibitory concentrations of Nystatin, Aspirin and EDTA. 
The results of effect Nystatin, Aspirin, and EDTA at subinhibitory concentrations against the biofilm formation of 28 C. albicans isolates which formed the strong biofilm, revealed that the Inhibition activity of biofilm formation by nystatin was stronger relative to Aspirin and EDTA, and this antifungal agent had antibiofilm effect even though at very low concentrations (table 3).

Table 3. The percentages of biofilm reduction by Aspirin, EDTA and Nystatin against Candida albicans at different subinhibitory concentrations.

\begin{tabular}{|c|c|c|c|c|c|c|c|}
\hline \multirow[b]{2}{*}{ Antibiofim agent $(\mu \mathrm{g} / \mathrm{ml})$} & \multicolumn{6}{|c|}{ Biofilm reduction (\%) } & \multirow{2}{*}{$\begin{array}{c}\text { Chi- } \\
\text { Square } \\
\left(\chi^{2}\right)\end{array}$} \\
\hline & 1000 & 500 & 250 & 125 & 62.5 & 31.25 & \\
\hline Aspirin & $61.90-70.51 \%$ & $29.75-34.25 \%$ & $8.95-10.71 \%$ & $1.54-5.18 \%$ & $12.01-14.33 \%$ & $2.35-8.58 \%$ & $12.63 * *$ \\
\hline \multirow[t]{2}{*}{ EDTA } & $54.43-60.12 \%$ & $48.27-51.29 \%$ & $1.83-3.27 \%$ & $0.74-2.08 \%$ & $4.00-5.89 \%$ & $26.19-28.65 \%$ & $11.08 * *$ \\
\hline & \multicolumn{6}{|c|}{ Biofilm reduction (\%) } & --- \\
\hline Antibiofim agent $(\mu \mathrm{g} / \mathrm{ml})$ & 100 & 50 & 25 & 12.5 & 6.25 & 3.125 & -- \\
\hline Nystatin & $76.66-83.30 \%$ & $69.51-75.80 \%$ & $44.86-57.15 \%$ & $29.49-34.35 \%$ & $9.12-10.70 \%$ & $2.86-4.22 \%$ & $13.46^{* *}$ \\
\hline
\end{tabular}

$* *(\mathrm{P} \leq 0.01)$.

EDTA (Ethylenediaminetetraacetic Acid): The effect of three antibiofilm agents (Nystatin, Aspirin and EDTA) on the nystatin resistant $C$. albicans isolate $5(\mathrm{MIC}=100 \mu \mathrm{g} / \mathrm{ml})$ was summarized at the figure 3 and table 4 .

Table 4. The absorbance of biofilm formation of Candida albicans (isolate 5) at different subinhibitory concentrations of Aspirin and EDTA.

\begin{tabular}{|c|c|c|c|c|c|c|c|}
\hline \multirow[b]{2}{*}{ Antibiofim agent $(\mu \mathrm{g} / \mathrm{ml})$} & \multicolumn{6}{|c|}{ O.D. $(630 \mathrm{~nm})$} & \multirow{2}{*}{ LSD value } \\
\hline & 1000 & 500 & 250 & 125 & 62.5 & 31.25 & \\
\hline Aspirin & $0.581 \mathrm{~b}$ & $1.138 \mathrm{a}$ & $1.211 \mathrm{a}$ & $1.589 \mathrm{a}$ & $1.384 \mathrm{a}$ & $1.050 \mathrm{a}$ & $0.456 *$ \\
\hline \multirow[t]{2}{*}{ EDTA } & $0.695 \mathrm{~d}$ & $0.808 \mathrm{~cd}$ & $1.505 \mathrm{ab}$ & $1.601 \mathrm{a}$ & $1.509 \mathrm{ab}$ & $1.195 \mathrm{bc}$ & $0.398 *$ \\
\hline & \multicolumn{6}{|c|}{ O.D. (630nm) } & \\
\hline Antibiofim agent $(\mu \mathrm{g} / \mathrm{ml})$ & 100 & 50 & 25 & 12.5 & 6.25 & 3.125 & --- \\
\hline Nystatin & $0.262 \mathrm{~d}$ & $0.411 \mathrm{~cd}$ & $0.724 \mathrm{bc}$ & $1.030 \mathrm{~b}$ & $1.401 \mathrm{a}$ & $1.580 \mathrm{a}$ & $0.377 *$ \\
\hline
\end{tabular}

Means having with the different letters in same row differed significantly.

$*(\mathrm{P} \leq 0.05)$.

O.D. of positive control $=0.063$

O.D. of negative control $=1.569$

\section{EDTA (Ethylenediaminetetraacetic Acid):} The highest antibiofilm activity by Nystatin were demonstrated at the subinhibitory concentration $50 \mu \mathrm{g} /$ $\mathrm{ml}$ with biofilm eradication percent $(75.80 \%)$, while the lowest antifungal effect (2.86-10.70\%) was at very low concentrations $(3.125-6.25 \mu \mathrm{g} / \mathrm{ml})$. Also, there was an obvious biofilm eradication of Aspirin and EDTA at the concentrations 500 and $1000 \mu \mathrm{g} / \mathrm{ml}$ but the effect of aspirin at the concentration $1000 \mu \mathrm{g} / \mathrm{ml}(70.51 \%)$ is more than EDTA $(60.12 \%)$ in contrast with the concentration $500 \mu \mathrm{g} / \mathrm{ml}$, it was found that the effect of EDTA (51.29\%) is more than aspirin (34.25\%). The effect of other concentrations $(31.25-250 \mu \mathrm{g} / \mathrm{ml})$ on the biofilm formation was not significant in comparison with the higher concentrations. The results revealed that nystatin at low concentration showed a significant effect as antifungal and antibiofilm agent in comparison with the high concentrations of aspirin and EDTA.

Concerning inhibition of biofilm production in the presence of subinhibitory concentrations of the Nystatin, the present study reflected more promising significant effects for treatment with this antifungal agent $(75.80 \%$ reduction) which are more than studies reported by other investigators, as in El-Houssaini et al. (2019) ${ }^{(28)}(30.86 \%$ reduction), and the study of Redding et al. (2009) ${ }^{(29)}(70 \%$ 
reduction). Many studies showed that the treatment of clinical C. albicans isolates with subinhibitory nystatin, concentrations significantly decreased production of extracellular hydrolases, Also, the greatest inhibitory effect on phospholipase and aspartyl protease production and a noticeable significant impact on inhibiting biofilm formation of $C$. albicans clinical isolates ${ }^{(28)}$. De Prijck and coworkers investigated the effect of nystatin released from modified polydimethyl siloxane disk as a model for incorporating antifungals in medical devices against biofilm formation by Candida spp. Nystatin exhibited a concentration-dependent inhibitory effect on Candida biofilm formation in a microtiter plate ${ }^{(30)}$.

It was demonstrated that EDTA alone (at 25 and $2.5 \mathrm{mM}$ ) significantly reduced fungal metabolic activity in preformed biofilms. Also, EDTA combined with fluconazole significantly reduced the growth of biofilm when compared to biofilm treated with fluconazole alone ${ }^{(31)}$. EDTA resulted in partial reduction of catheter colonization by $C$. albicans, As previously reported, the combination of EDTA with low minocycline concentration $(0.1 \mathrm{mg} / \mathrm{ml})$ resulted in a significant decrease in catheter colonization but combined with higher concentrations of minocycline resulted in complete eradication of C. albicans biofilms ${ }^{(32)}$.

According to the results of effect of aspirin on the biofilm formation in C. albicans, it was found that cyclooxygenase-dependent synthesis of fungal prostaglandins is important for both biofilm development and morphogenesis in C. albicans and may act as a regulator in these physiological processes and that aspirin possesses potent antibiofilm activity in vitro and could be useful in combined therapy with conventional antifungal agents in the management of some biofilmassociated Candida infections ${ }^{(33)}$. Studies have shown that cyclooxygenase (COX) inhibitors, such as aspirin, ibuprofen, and indomethacin, combined with fluconazole can significantly reduce Candida adhesion and biofilm development and increase fluconazole susceptibility; the MIC of fluconazole can be decrease from 64 to $2 \mu \mathrm{g} / \mathrm{ml}$ when used in combination with ibuprofen. In addition, in vivo studies have also confirmed the antifungal activities of these inhibitors ${ }^{(34)}$. Aspirin alone or in combination with conventional antifungal drugs is also beneficial for the treatment of vulvovaginal candidiasis by inhibition of cyclooxygenases in host cells and by inhibition of 3-hydroxyoxylipins in C. albicans ${ }^{(35)}$.

\section{Conclusion}

The present findings indicated to the role of some drugs or compounds such as Aspirin and EDTA when used with effective antifungal agents in control the infections of Candida albicans especially in the women with vulvovaginitis by inhibition the biofilm formation which considered as the main virulence factor in Candida species.

\section{Source of Funding: Authors}

Ethical Clearance: Yes

Conflict of Interest: Nil

\section{References}

1. El-Houssaini HH, Elnabawy OM, Nasser HA, Elkhatib WF. Influence of subinhibitory antifungal concentrations on extracellular hydrolases and biofilm production by Candida albicans recovered from Egyptian patients. BMC Infect Dis. 2019; 19(1):54.

2. Ganguly S, Mitchell AP. Mucosal biofilms of Candida albicans. Current Opinion In Microbiology. 2011; 14(4), 380-385.

3. Theodoropoulos DS, Stockdale CK, Duquette DR, Morris MS. Inhalant allergy compounding the chronic vaginitis syndrome: characterization of sensitization patterns, comorbidities and responses to sublingual immunotherapy. Archives of Gynecology and Obstetrics. 2016; 294(3), 541-548.

4. Nikoomanesh F, Roudbarmohammadi S, Khoobi M, Haghighi F, Roudbary M. Design and synthesis of mucoadhesive nanogel containing farnesol: investigation of the effect on HWP1, SAP6 and Rim101 genes expression of Candida albicans in vitro. Artificial Cells, Nanomedicine, and Biotechnology. 2019; 47(1), 64-72.

5. De Oliveira Santos GC, Vasconcelos CC, Lopes AJ, de Sousa Cartágenes MDS, Allan Filho KDB, Do Nascimento FR, De Andrade Monteiro C. Candida infections and therapeutic strategies: mechanisms of action for traditional and alternative agents. Frontiers In Microbiology. 2018; 9: 1351.

6. Pathirana RU, McCall AD, Norris HL, Edgerton M. Filamentous non-albicans Candida species adhere to Candida albicans and benefit from dual biofilm growth. Frontiers in microbiology. 2019; 10: 1188.

7. Aboualigalehdari E, Sadeghifard N, Taherikalani 
M. Anti-biofilm Properties of Peganum harmala against Candida albicans. Osong Public Health Res Perspect. 2016; 7(2):116-118.

8. CLSI, Clinical and Laboratory Standards Institute. Performance Standards for Antimicrobial Susceptibility Testing; Twentieth Informational Supplement. CLSI document M100-S20. Wayne, PA, 2010.

9. Khodavandi A, Harmal NS, Alizadeh F. Comparison between allicin and fluconazole in Candida albicans biofilm inhibition and in suppression of HWP1 gene expression. Phytomedicine. 2011; 19:56-63.

10. SAS, Statistical Analysis System, User's Guide. Statistical Version $9.1^{\text {th }}$ ed. SAS. Inst. Inc. Cary. N.C. USA, 2012.

11. Gao M, Wang $\mathrm{H}$, Zhu L. Quercetin assists fluconazole to inhibit biofilm formations of fluconazole-resistant Candida albicans in in vitro and in vivo antifungal managements of vulvovaginal candidiasis. Cell Physiol Biochem. 2016; 40:727-742.

12. Sherry L, Kean R, McKloud E, O'Donnell LE, Metcalfe R, Jones BL, Ramage G. Biofilms formed by isolates from recurrent vulvovaginal candidiasis patients are heterogeneous and insensitive to fluconazole. Antimicrob Agents Chemother. 2017; 61:e01065-17.

13. Shrief R, Zaki EM, El-Sehsah EM, Ghaleb S, Mofreh M. Study of Antifungal Susceptibility, Virulence Genes and Biofilm Formation in Candida albicans. The Open Microbiology Journal. 2019; 13, 241-248.

14. Mohammed NA, Ajah HA, Abdulbaqi NJ. Detection the prevalence of adhesins and extracellular hydrolytic enzymes genes in Candida albicans biofilm formation Iraqi Journal of Science.2017; 58: 988-1000.

15. Filardo S, Di Pietro M, Tranquilli G, Sessa, R. Biofilm in Genital Ecosystem: A Potential Risk Factor for Chlamydia trachomatis Infection. Can J Infect Dis Med Microbiol. 2019; 2019: 1672109.

16. Galocha $M$, Pais $P$, Cavalheiro M, Pereira D, Viana R, Teixeira MC. Divergent Approaches to Virulence in C. albicans and C. glabrata: Two Sides of the Same Coin. Int J Mol Sci. 2019; 20(9):2345.

17. Nenoff P, Krüger C, Neumeister C, Schwantes U, Koch D. In vitro susceptibility testing of yeasts to nystatin - low minimum inhibitory concentrations suggest no indication of in vitro resistance of Candida albicans, Candida species or non-Candida yeast species to nystatin. Clin Med Investig. 2016; 1: 71-76.

18. El-Din SS, Reynolds, MT, Ashbee, HR, Barton, $\mathrm{RC}$, Evans. EGV. An investigation into the pathogenesis of vulvovaginal candidosis. Sex. Transm. Infect. 2001; 77:179-183.

19. Richter SS, Galask RP, Messer SA, Hollis RJ, Diekema DJ, Pfaller MA. Antifungal susceptibilities of Candida species causing vulvovaginitis and epidemiology of recurrent cases. J Clin Microbiol. 2005; 43(5):2155-2162.

20. Al-Bakri AG, Othman G, Bustanji Y. The assessment of the antibacterial and antifungal activities of aspirin, EDTA and aspirin-EDTA combination and their effectiveness as antibiofilm agents. J Appl Microbiol. 2009; 107:280-6.

21. Cederlund H, Mardh PA. Antibacterial activities of non-antibiotic drugs. J Antimicrob Chemother. 1993; 32, 355-365.

22. Erb-Downward JR, Noverr MC. Characterization of prostaglandin E2 production by Candida albicans. Infect Immun. 2007; 75:3498 -3505.

23. Zhou Y, Wang G, Li Y, Liu Y, Song Y, Zheng W, Zhang N, Hu X, Yan S, Jia J. In vitro interactions between aspirin and amphotericin $\mathrm{B}$ against planktonic cells and biofilm cells of Candida albicans and C. parapsilosis. Antimicrob Agents Chemother.2012; 56:3250 -3260.

24. Gil ML, Casanova M, Martínez JP. Changes in the cell wall glycoprotein composition of Candida albicans associated to the inhibition of germ tube formation by EDTA. Arch Microbiol. 1994; 161: 489-494.

25. Arias-Moliz MT, Ferrer-Luque CM, EspigaresRodríguez E, Liébana-Ureña J, Espigares-García M. Bactericidal activity of phosphoric acid, citric acid, and EDTA solutions against Enterococcus faecalis. Oral Surg Oral Med Oral Pathol Oral Radiol Endod. 2008; 106(2):e84-e89.

26. Sen BH, AKdeniz BG, Denizci AA. The effect of ethylenediamine- tetraecetic acid on $\mathrm{C}$ albicans. OOOE. 2000; 90:651-655.

27. Lambert RJW, Hanlon GW, Denyer SP. The synergistic effect of EDTA/antimicrobial combinations on Pseudomonas aeruginosa. J Appl Microbiol. 2004; 96: 244-253. 
28. El-Houssaini HH, Elnabawy OM, Nasser HA, Elkhatib WF. Correlation between antifungal resistance and virulence factors in Candida albicans recovered from vaginal specimens. Microbial Pathogenesis. 2019; 128: 13-19.

29. Redding S, Bhatt B, Rawls HR, Siegel G, Scott K, Lopez-Ribot J. Inhibition of Candida albicans biofilm formation on denture material. Oral Surg Oral Med Oral Pathol Oral Radiol Endod. 2009; 107(5): 669-72.

30. De Prijck K, De Smet N, Honraet K. Inhibition of Candida albicans biofilm formation by antimycotics released from modified polydimethyl siloxane. Mycopathologia 2010; 169(3): 167-74.

31. Casalinuovo IA, Sorge R, Bonelli G, Di Francesco P. Evaluation of the antifungal effect of EDTA, a metal chelator agent, on Candida albicans biofilm. Eur Rev Med Pharmacol Sci. 2017; 21(6):14131420 .
32. Raad I, Hachem R, Tcholakian RK, Sherertz R. Efficacy of minocycline and EDTA lock solution in preventing catheter-related bacteremia, septic phlebitis, and endocarditis in rabbits. Antimicrob Agents Chemother. 2002; 46(2): 327-32.

33. Alem, M. A. \& Douglas, L. J. (2004). Effects of aspirin and other nonsteroidal anti-inflammatory drugs on biofilms and planktonic cells of Candida albicans. Antimicrob. Agents Chemother. 48, 41-47.

34. Liu, X., Wang, D., Yu, C., Li, T., Liu, J., and Sun, S. (2016). Potential antifungal targets against a Candida biofilm based on an enzyme in the arachidonic acid cascade-a review. Front. Microbiol. 7:1925.

35. Deva, R., Ciccoli, R., Kock, L., and Nigam, S. (2001). Involvement of aspirin-sensitive oxylipins in vulvovaginal candidiasis. FEMS Microbiol. Lett. 198, 37-43. 